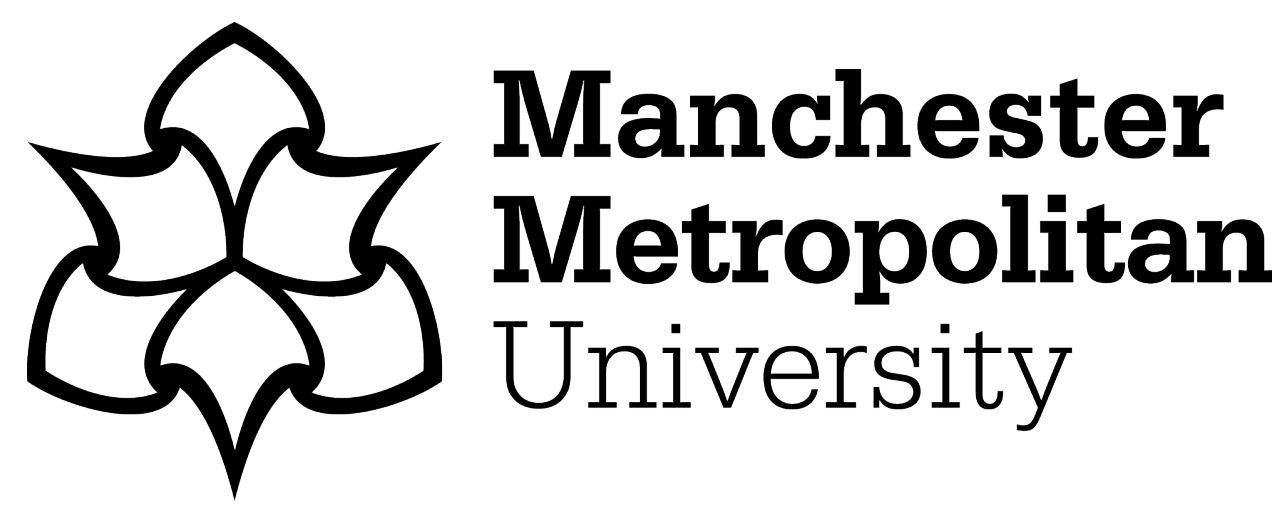

Mulrooney, KJD, van de Ven, K, McVeigh, J ORCID logoORCID: https://orcid.org/0000-0001-5319-6885 and Collins, R (2019) Commentary: Steroid Madness- has the dark side of anabolic-androgenic steroids (AAS) been over-stated? Performance Enhancement and Health, 6. pp. 98-102. ISSN 2211-2669

Downloaded from: https://e-space.mmu.ac.uk/624825/

Version: Accepted Version

Publisher: Elsevier

DOI: https://doi.org/10.1016/j.peh.2019.03.001

Usage rights: Creative Commons: Attribution-Noncommercial-No Derivative Works 4.0

Please cite the published version 


\section{Commentary: Steroid Madness- Has the dark side of anabolic-androgenic steroids (AAS) been over- stated?}

\section{Introduction}

Recently the journal Performance Enhancement \& Health put out a call to produce a special issue on the dark side of human enhancement, including the use of legal and illegal substances, leading us to ponder whether the "dark side" of anabolic-androgenic steroids (from here on, "steroids") has been overstated. In this commentary, we will briefly engage with this question by unpacking what we describe here as the "narrative of harm", which tends to dominate discourses on steroid use in wider society. We then consider an alternative perspective on steroid use which focuses on the users' experience and understanding, with particular attention to the role of pleasure. Finally, we conclude by exploring some of the negative policy consequences arising from the dominance of the "narrative of harm" and advance a regulatory approach grounded in rational research and informed discussions around both the pleasures and pains of steroid use. A more developed version of this argument can be found in the forthcoming collection Human Enhancement Drugs, published by Routledge in 2019 (Mulrooney, van de Ven, McVeigh, \& Collins, forthcoming).

\section{The Narrative of Harm}

The most pervasive facet of the narrative of harm is that steroids pose serious health risks. Media and political discourses in particular tend to provide a sense that using these drugs is "akin to being a gun powder keg about to explode" (Soni \& Nasrulla, 2018) or that users are on a "deadly crusade to get ripped" (Gorman, 2017). Yet, the reality is much more complex. For instance, the most commonly identified side effects are cosmetic in nature, such as oily skin (leading to acne) and fluid retention, which are generally reversible with cessation (Andrews, Magee, Combest, Allard, \& Douglas, 2018; van Amsterdam, Opperhuizen, \& Hartgens, 2010). Nevertheless, in addition to health risks such as testicular atrophy, increased blood pressure, suppression of gonadotropins and reduced insulin sensitivity (see e.g. Rasmussen et al. 2016; 2017; 2017); Christou et al. 2017; Kanayama et al. 2015; Nieschlag \& Vorona 2015; Rahnema et al. 2014; Rasmussen et al. 2016; Pope et al. 2014) several long-term health risks have been associated with using steroids such as cardiovascular disease (Baggish et al., 2017) and cognitive deficiencies (Kaufman et al., 2015). Evidently, the potential for harm exists, however, such harms need to be contextualized. In a simple use vs. non-use dichotomy, of course people who use steroids are at greater risk of developing health harms related to their use than people who do not use. Indeed, the bottom line for current health policy is that non-medical steroid use is bad for your health.

However, although it is often stated by health authorities and the media that steroids are harmful, data are lacking as to precisely how harmful they are. Most knowledge about the harmful effects of steroids is based on low level evidence, such as expert opinion, case reports or small observational studies, while clinical trials to study the efficacy and long-term effects of steroid use are absent (Smit \& de Ronde, 2018). Yet, instead of acknowledging that we lack a comprehensive understanding of the health risks of steroid use, a "guilty until proven innocent" stance is often taken. Not only does this hamper our understanding of the health risks of these substances but also the advancement of medical research wanting to explore their therapeutic benefits. While the extent to which steroid use leads to critical health risks is unclear, there are other indicators we may draw on to gain a better understanding of the relative risks of these substances, for example, when comparing them to other illicit drugs. In a number of studies exploring relative drugs harms, steroids consistently appear low on the list for general harm as well as for physical, psychological and social harm to both users and society (e.g. Nutt, King, \& Phillips, 2010; van Amsterdam, Nutt, Phillips, \& van den Brink, 2015; van Amsterdam, Opperhuizen, Koeter, \& van den Brink, 2010). 
Furthermore, we must also be considerate to relative risks between users. Indeed, wthere is evidence to suggest steroids do pose health risks, important contextual information is often left out such as, for example, the role of pre-existing health conditions, the use of unverified black-market products, the type of steroids used and/or the dosage and in particular, the length of steroid using career. For instance, years of high dosages may impair testosterone function and some users may not themselves recover completely from anabolic steroid induced hypogonadism (ASIH) without the assistance of testosterone replacement therapy (TRT). Yet, perhaps one of the key aspects of blurring the line between the "pleasures and pains" of steroid use is the failure to differentiate between use and abuse, though this is not foreign to discourses on drug use. Rather, it is the accumulation of factors, such as longer steroid cycles, increased dosages and poly-drug use, which increase the public health risk and, therefore, depending on their use patterns some users will run greater health risks than others. Taken together, discussions on steroid use must clearly distinguish between health harms that are likely to be centrally important to users in terms of both the probability of occurrence and potential severity, as well as the relativity of risk in terms of steroid use generally and between "typologies" of steroid users themselves (Christiansen, Vinther, \& Liokaftos, 2017).

Closely connected to individual health harms, a frequently cited side effect of non-medical steroid use is aggression and violence. Indeed, since the mid-1980s, the notion that steroid use leads to aggressive or violent behaviour became widespread, giving rise to the term 'roid rage', used to denote steroid-related aggression (Dunn, 2014). Once again, this facet of the narrative of harm is amplified by the media and law enforcement discourses which often recount how steroids played a central role in particularly brutal acts of violence such as, the case of wrestling star Chris Benoit (Chappell, 2007) or, more recently, the London Bridge terrorist attack (BBC, 2018). Although the animal literature has found a direct, positive relationship between testosterone and increased aggressive behaviour (McGinnis, 2006; Melloni, Connor, Xuan Hang, Harrison, \& Ferris, 1997), providing important insights into some of the behavioural consequences of steroid use, it does not and cannot capture all aspects of the human experience. Indeed, studies that have examined the relationship between aggressive behaviour and substance use by humans show a much more complex picture. While testosterone may facilitate both aggressive and rewarding behaviour in humans (see Dreher et al, 2016), in general, the relationship between substance use (including steroids) and aggressive behaviour is likely accounted for by third variable factors, such as personality traits, neuropsychological risks, environmental influences, socio-economic status, poly-substance use and, with the exception of alcohol, is not causally related (Lundholm, Frisell, Lichtenstein, \& Langstrom, 2015; Tomlinson, Brown, \& Hoaken, 2016), highlighting the complexity of hormone/behaviour-relations.

Lastly, the caricature of non-medical steroid users as narcissistic, self-absorbed 'gym bros' suffering from body image issues, provides an equally simplistic account of user motivations and ignores the spectrum of user typologies. In media articles, for example, steroid users are often portrayed as young adults or teenagers who are insecure about their body and are experiencing a "crisis of male ego" (Walsh, 2018) by seeking the "ripped Loved Island look" (Burrows, 2017). Yet, typically, a person's first experience using steroids is reported to occur in their mid to late twenties (McVeigh \& Begley, 2017), with many steroid users having an above average education and income, and not being involved in sports (Christiansen et al., 2017; Cohen, Collins, Darkes, \& Gwartney, 2007). To this end, there is an increasing body of research which shows that there is substantial variability in steroid-using populations in terms of motivations for use, health risk potential and health seeking behaviours (Christiansen et al., 2017; van de Ven et al., 2018b; Zahnow et al., 2018). Indeed, while some use for cosmetic reasons (e.g., to increase muscle mass and strength) others will use these substances to improve sporting performance, for anti-ageing purposes, to increase energy levels and/or to recover more quickly from an injury (Begley et al., 2017). 
A specific subtype of body image disorder linked to this group is muscle dysmorphia, often referred to as "bigorexia" in the media, which was first described in the early 90s (Pope Jr, Katz, \& Hudson, 1993). The main feature of muscle dysmorphia is body dissatisfaction, in particular regarding one's muscles, which may lead individuals to use steroids, consume supplements, strictly control their diets, engage in excessive physical exercise, and so on (Olivardia, Pope, \& Hudson, 2000). Yet, there is no solid evidence as to how many people who use steroids actually have or will develop a body image disorder, or what the association is between the two. While some studies point towards an association (e.g. Rohman, 2009), others do not find an association and, for example, show that the attachment style of a person is an important predictor for someone to develop muscle dysmorphia (e.g. Fabris, Longobardi, Prino, \& Settanni, 2018). Perhaps most concerning, in a recent systematic review of the literature on muscle dysmorphia, Sandgren and Lavallee (2018) concluded that the "methodological quality of recent muscle dysmorphia research was considered low due to a lack of clinical samples, measurements not using validated cut-off scores, and the research designs".

\section{The User's Voice and the Pleasures of Steroid Use}

Research in the field of alcohol and psychoactive drugs has highlighted the importance of acknowledging the benefits and pleasurable effects of substance use and the use of substances by healthy individuals (e.g. Hamilton \& Aldridge, 2019; Power, 2018; d'Angelo, Savulich, \& Sahakian, 2017; Holt \& Treloar, 2008; O'Malley \& Valverde, 2004; Ritter, 2014; Winstock \& Nutt, 2013). Following this line, an implication of the narrative of harm is that it tends to overlook and ignore the role of pleasure in the consumption of steroids and, even where this may be acknowledged, paternalism and morality tend to take precedence over individual choice. In terms of the latter point, it goes without saying that this position is at odds with a number of riskier socially accepted and legalized pursuits such as the consumption of tobacco and alcohol, and, more recently, surgical and non-surgical cosmetic enhancement.

Indeed, with respect to these pursuits, Western liberal democracies generally concede that consenting adults have the right to choose pleasure at the risk of pain (or even injury or death) and we accept this in many facets of life more broadly (e.g. sport) so long individual freedoms do not impinge on the 'common good'. Yet, there is a stark contrast between the way society treats cosmetic steroid use as compared to non-surgical cosmetic enhancement such as the use of Botox and dermal filler or surgical enhancement such as breast augmentation or blepharoplasty (eyelid surgery), despite the relative risks involved (Balk, Earley, Avendano, \& Raman, 2016; Brennan, Wells, \& Van Hout, 2018). Indeed, while both surgical and non-surgical procedures have become increasingly normalized and arguably celebrated (e.g., Vogue) as a personal prerogative of self-improvement (Featherstone, 2010), steroid use remains largely pathologized despite questions being raised about the relative harm of these substances. This may be, in part, because of the legal/regulatory context in which these respective practices occur, but that is only because policy makers have chosen to deal with this particular form of enhancement through repression.

We often overlook the fact that there will be many users who will use these substances for their immediate gratification (e.g., feelings of strength) or delayed gratification from 'higher' objectives (e.g., constructive efforts/functional enhancement). Indeed, there is a plethora of self-reported data with regard to the role of "pleasures" in the consumption of steroids (e.g. Monaghan, 2001, 2002; Kimergård, 2015; Underwood, 2017). For instance, while Monaghan (2002) notes that bodybuilders tend to sharply contrast themselves with 'other' drug takers, often based on their pursuit of a "higher objective than pleasure" in contrast to, for example, the pleasure of getting high, he also points out that "bodybuilders derive aesthetic pleasure from their own and other members' body modification practices", linked to both feelings and constructive efforts. In other words, while "the 'highs' associated with chemical bodybuilding are achieved rather than pharmacological", they are nonetheless pleasure inducing and part of the appeal 
of drug taking in this context. In addition to the delayed gratification which comes from body/performance modification, it is not unusual for users to report pleasurable feelings such as increased libido, greater confidence and increased wellbeing and strength (Begley et al., 2017; Underwood, 2017).

Given the centrality of pleasure for many users in the consumption of these substances, pleasure is an essential part of a coherent and reasoned response to steroid consumption. The current "pathology paradigm" (Mugford, 1988; cited in Moore, 2008) engrained in the narrative of harm is dominated almost exclusively by individual and social risks with little to no acknowledgment of pleasure as a benefit in its own right. This is particularly relevant considering the questions raised above with respect to absolute and relative risk, the notion of individual choice and a risk/benefit analysis. Perhaps most worrisome, failing to acknowledge the role of pleasure and other benefits in the consumption of these drugs may hinder our ability to address the phenomenon and ultimately curbs advances in regulatory frameworks. It is to this we now turn.

\section{Implications of the Narrative of Harm}

Our central point of contention with the narrative of harm is the way in which the dominance of the discourses that comprise it have come to occupy discussions around steroids to the exclusion of others. The key problem being that, without nuance, the public and policy-makers are presented with a distorted reality from which to respond to steroid use. Indeed, there are a number of serious implications driven by this narrative and the pre-cautionary principle it tends to emphasize. Chiefly, a narrative centred on public health harms, the potential for violent behaviour and psychological disturbance naturally prioritizes repressive means to combat the issue. Add to this the incompatibility of harm reduction with two other dominant narratives that tend to dominate discussion on steroids, that of doping in sport and the use of steroids by youth, and it is not surprising that punitive mechanisms lead the charge in what has been called the "war on doping".

Extreme examples include Denmark and Belgium where every-day gym users are subject to drug testing regimes with punitive implications (Christiansen, 2011; van de Ven, 2016; van de Ven \& Mulrooney, 2017; van de Ven \& Mulrooney, 2014). Furthermore, a number of countries (e.g. Australia, Sweden, and the US) have rescheduled steroids so that their production, sale and even consumption come with increasingly harsh penalties (van de Ven \& Mulrooney, 2014). For example, increased attention on violence in Sydney's night time economy formed part of the arguments which led to a raft of legislative changes, including rescheduling steroids as a schedule I drug and subsequently increasing the maximum sentence for the illicit supply of steroids to 25 years (van de Ven, Dunn, \& Mulrooney, 2018a). As evidenced in other drug markets (e.g. Caulkins \& Reuter, 2006; Lenton \& Heale, 2000; Volkow, Poznyak, Saxena, Gerra, \& Network, 2017), this repressive approach of criminalizing use has resulted in its own set of harms to users such as subjecting users to prison or felony convictions, as happens in some jurisdictions, which can destroy a person's employment and educational opportunities, adversely impacting their own lives and the lives of their families.

Furthermore, even where harm reduction initiatives are advanced, the narrative of harm surrounding steroids leads to the natural conclusion that these drugs need to be controlled if not by the threat of punishment than at least by making them more difficult to access. The issue with this, as much research has shown (e.g. Caulkins \& Reuter, 2006), is that where there is demand there is supply and so users continue to consume, however, their sources and consumption practices are clandestine instead of medically regulated (Fincoeur, van de Ven, \& Mulrooney, 2015). Indeed, many of the health harms so central to the narrative of harm could be more easily discovered by adopting a public health-oriented model of addressing the issue of steroid consumption. For instance, by not accepting the pleasurable 
effects or low risks of using certain pharmaceuticals, healthcare providers, such as physicians, may be dissuaded from providing medical services to people who choose to continue to their pharmaceutical drug use for non-medical reasons (i.e., non-medical steroid use). Importantly, many users know harm is only part of the story and so the primary definers of "the steroid problem" may lose credibility. Thus, it is perhaps not surprising that steroid users tend to report rather negative experiences in their interactions with medical professionals (Dunn, Henshaw, \& McKay, 2016; Hope et al., 2013; Zahnow, McVeigh, Ferris, \& Winstock, 2017). This is particularly relevant when it comes to attempting to engage users in harm reduction practices.

\section{Conclusion}

This commentary should not be read as an attempt to deny any harmful properties nor to promote the use of these substances. Rather, our intention is to question and critique the dominance of the narrative of harm, in light of a more nuanced appraisal of the evidence, and, most importantly, to highlight that in over-stating the dark side of steroids a skewed narrative has emerged which has the potential to increase harms in the name of public protection. The failure of the media, politicians and some academics to report this more complex and nuanced picture, focusing instead on isolated case reports of harms and tragedies, misinforms the public and policy-makers. This understandably directs the dialogue and policy into punitive territory and sows' mistrust in those with otherwise benevolent intentions. Alternatively, we argue, that a more realistically balanced approach to these drugs, absent from morality and sensationalism, considerate of the users' perspective and backed by scientific research, increases the capacity to reduce evidenced harms. Indeed, while there is evidence to suggest steroids are harmful, the narrative of harm which tends to dominate discourses on steroid consumption often fails to consider questions around the relative nature of harms and to weigh such risks against a plethora of self-reported outcomes due to functional enhancement, in addition to any potential immediate gratification for users. As such, it will help us to inject pleasure into the discourses on steroid use and its regulation, to have rational and critical debates on achieving pleasure while minimizing established associated risks, something that is particularly important in a world that appears increasingly willing and indeed eager to explore the opportunities for human enhancement.

\section{References}

Andrews, M.A., Magee, C.D., Combest, T.M., Allard, R.J., \& Douglas, K.M. (2018). Physical Effects of Anabolic-androgenic Steroids in Healthy Exercising Adults: A Systematic Review and Metaanalysis. Current Sports Medicine Reports, 17(7), 232-241. doi:10.1249/jsr.0000000000000500

Baggish, A.L., Weiner, R.B., Kanayama, G., Hudson, J.I., Lu, M.T., Hoffmann, U., \& Pope, H.G. (2017). Cardiovascular Toxicity of Illicit Anabolic-Androgenic Steroid Use. Circulation, 135(21), 19912002.

Balk, E.M., Earley, A., Avendano, E.A., \& Raman, G. (2016). Long-term health outcomes in women with silicone gel breast implants: A systematic review. Annals of Internal Medicine, 164(3), 164-175. doi:10.7326/M15-1169

BBC. (2018). London Bridge terror attackers 'took steroids' before incident. BBC News. Retrieved from https://www.bbc.com/news/uk-43005590

Begley, E., McVeigh, J., Hope, V., Bates, G., Glass, R., Campbell, J., . . Smith, J. (2017). Image and Performance Enhancing Drugs: 2016 National Survey Results Retrieved from Liverpool, UK: http://ipedinfo.co.uk

Brennan, R., Wells, J.S.G., \& Van Hout, M. (2018). "Saving Face": An Online Study of the Injecting Use of DIY Botox and Dermal Filler Kits. Plastic Surgery, 26(3), 154-159.

doi:10.1177/2292550318767432 
Burrows, T. (2017). Steroid use quadruples in just one year as experts say the pressure to get the 'Love Island look' is driving record numbers of young men to body-building drugs. Daily Mail. Retrieved from https://www.dailymail.co.uk/news/article-4739408/Steroid-use-quadruplesjust-one-year.html

Caulkins, J.P., \& Reuter, P. (2006). Illicit drug markets and economic irregularities. Socio-Economic Planning Sciences, 40(1), 1-14. doi:https://doi.org/10.1016/i.seps.2004.08.002

Chappell, T. (2007). Steroid found in body of dead wrestler Benoit. Reuters. Retrieved from https://www.reuters.com/article/us-usa-wrestler/steroid-found-in-body-of-dead-wrestlerbenoit-idUSN1724458420070717

Christiansen, A.V. (2011). Bodily violations: testing citizens training recreationally in gyms (M. McNamee \& V. Møller Eds. 1 ed.). UK: Routledge

Christiansen, A.V., Vinther, A.S., \& Liokaftos, D. (2017). Outline of a typology of men's use of anabolic androgenic steroids in fitness and strength training environments*. Drugs: Education, Prevention and Policy, 24(3), 295-305. doi:10.1080/09687637.2016.1231173

Christou et al. 2017

Cohen, J., Collins, R., Darkes, J., \& Gwartney, D. (2007). A league of their own: demographics, motivations and patterns of use of 1,955 male adult non-medical anabolic steroid users in the United States. Journal of the International Society of Sports Nutrition, 4(12), 1-14. doi:10.1186/1550-2783-4-12

d'Angelo, L.S.C., Savulich, G., \& Sahakian, B.J. (2017). Lifestyle use of drugs by healthy people for enhancing cognition, creativity, motivation and pleasure. British Journal of Pharmacology, 174(19), 3257-3267. doi:10.1111/bph.13813

Dunn, M. (2014). Commentary on Lundholm et al. (2015): What came first, the steroids or the violence? Addiction, 110(1), 109-110. doi:10.1111/add.12752

Dunn, M., Henshaw, R., \& McKay, F.H. (2016). Do performance and image enhancing drug users in regional Queensland experience difficulty accessing health services? Drug Alcohol Rev, 35. doi:10.1111/dar.12363

Fabris, M.A., Longobardi, C., Prino, L.E., \& Settanni, M. (2018). Attachment style and risk of muscle dysmorphia in a sample of male bodybuilders. Psychology of Men \& Masculinity, 19(2), 273-281.

Featherstone, M. (2010). Body, Image and Affect in Consumer Culture. Body \& Society, 16(1), 193-221. doi:10.1177/1357034X09354357

Fincoeur, B., van de Ven, K., \& Mulrooney, K.J.D. (2015). The symbiotic evolution of anti-doping and supply chains of doping substances: how criminal networks may benefit from anti-doping policy. Trends in Organized Crime, 18(3), 229-250. doi:10.1007/s12117-014-9235-7

Gorman, G. (2017). The deadly crusade to get ripped. News.com.au. Retrieved from https://www.news.com.au/lifestyle/beauty/for-men/the-deadly-crusade-to-get-ripped/newsstory/0457a6e5a0e00ea49980e240fb991579

Hamilton, I., \& Aldridge, A. (2019). Drugs: researchers shouldn't just focus on the harms. UK: The Conversation

Holt, M., \& Treloar, C. (2008). Pleasure and drugs. Int J Drug Policy, 19(5), 349-352. doi:10.1016/j.drugpo.2007.12.007

Hope, V.D., McVeigh, J., Marongiu, A., Evans-Brown, M., Smith, J., Kimergård, A., . . Ncube, F. (2013). Prevalence of, and risk factors for, HIV, hepatitis B and C infections among men who inject image and performance enhancing drugs: a cross-sectional study. BMJ Open, 3(9). doi:10.1136/bmjopen-2013-003207

Kanayama et al. 2015 
Kaufman, M.J., Janes, A.C., Hudson, J.I., Brennan, B.P., Kanayama, G., Kerrigan, A.R., . . Pope, H.G., Jr. (2015). Brain and cognition abnormalities in long-term anabolic-androgenic steroid users. Drug Alcohol Depend, 152, 47-56. doi:10.1016/j.drugalcdep.2015.04.023

Kimergård, A. (2015). A qualitative study of anabolic steroid use amongst gym users in the United Kingdom: motives, beliefs and experiences. J Subst Use, 20. doi:10.3109/14659891.2014.911977

Lenton, S., \& Heale, P. (2000). Arrest, Court and Social Impacts of Conviction for a Minor Cannabis Offense under Strict Prohibition. Contemporary Drug Problems, 27(4), 805-833. doi:10.1177/009145090002700405

Lundholm, L., Frisell, T., Lichtenstein, P., \& Langstrom, N. (2015). Anabolic androgenic steroids and violent offending: confounding by polysubstance abuse among 10,365 general population men. Addiction, 110(1), 100-108. doi:10.1111/add.12715

McGinnis, M.Y. (2006). Anabolic Androgenic Steroids and Aggression: Studies Using Animal Models. Annals of the New York Academy of Sciences, 1036(1), 399-415. doi:10.1196/annals.1330.024

McVeigh, J., \& Begley, E. (2017). Anabolic steroids in the UK: an increasing issue for public health. Drugs: Education, Prevention and Policy, 24(3), 278-285. doi:10.1080/09687637.2016.1245713

Melloni, R.H., Connor, D.F., Xuan Hang, P.T., Harrison, R.J., \& Ferris, C.F. (1997). Anabolic-Androgenic Steroid Exposure During Adolescence and Aggressive Behavior in Golden Hamsters. Physiology \& Behavior, 61(3), 359-364. doi:https://doi.org/10.1016/S0031-9384(96)00373-3

Monaghan, L.F. (2001). Bodybuilding, drugs and risk. London: Routledge.

Monaghan, L.F. (2002). Vocabularies of motive for illicit steroid use among bodybuilders. Soc Sci Med, 55. doi:10.1016/s0277-9536(01)00195-2

Moore, D. (2008). Erasing pleasure from public discourse on illicit drugs: on the creation and reproduction of an absence. Int J Drug Policy, 19(5), 353-358. doi:10.1016/j.drugpo.2007.07.004

Mulrooney, K., van de Ven, K., McVeigh, J., \& Collins, R. (forthcoming). Steroid Madness - Has the darkside of AAS been over-stated? In K. Mulrooney, K. Van de Ven, \& J. McVeigh (Eds.), Edited collection on human enhancement drugs (HEDs). UK: Routledge.

Nieschlag \& Vorona 2015

Nutt, D.J., King, L.A., \& Phillips, L.D. (2010). Drug harms in the UK: a multicriteria decision analysis. The Lancet, 376(9752), 1558-1565. doi:https://doi.org/10.1016/S0140-6736(10)61462-6

O'Malley, P., \& Valverde, M. (2004). Pleasure, Freedom and Drugs: The Uses of'Pleasure' in Liberal Governance of Drug and Alcohol Consumption. Sociology, 38(1), 25-42. doi:10.1177/0038038504039359

Olivardia, R., Pope, H.G., \& Hudson, J.I. (2000). Muscle Dysmorphia in Male Weightlifters: A Case-Control Study. American Journal of Psychiatry, 157(8), 1291-1296. doi:10.1176/appi.ajp.157.8.1291

Pope et al. 2014

Power, J. (2019). Drug use can have social benefits, and acknlowledging that could improve rehabilitation. AU: The Conversation.

Rahnema et al. 2014

Rasmussen et al. 2016; 2017; 2017)

Ritter, A. (2014). Where is the pleasure? Addiction, 109(10), 1587-1588. doi:10.1111/add.12545

Rohman, L. (2009). The relationship between anabolic androgenic steroids and muscle dysmorphia: a review. Eat Disord, 17(3), 187-199. doi:10.1080/10640260902848477

Sandgren, S.S., \& Lavallee, D. (2018). Muscle Dysmorphia Research Neglects DSM-5 Diagnostic Criteria. Journal of Loss and Trauma, 23(3), 211-243. doi:10.1080/15325024.2018.1428484

Smit, D.L., \& de Ronde, W. (2018). Outpatient clinic for users of anabolic androgenic steroids: an overview. Neth J Med, 76(4), 167. 
Soni, A., \& Nasrulla, F. (2018). Be careful of these instant muscle builders. The Tribune. Retrieved from https://www.tribuneindia.com/news/trends/be-careful-of-these-instant-musclebuilders/631509.html

Tomlinson, M.F., Brown, M., \& Hoaken, P.N.S. (2016). Recreational drug use and human aggressive behavior: A comprehensive review since 2003. Aggression and Violent Behavior, 27, 9-29. doi:https://doi.org/10.1016/i.avb.2016.02.004

Underwood, M. (2017). Exploring the social lives of image and performance enhancing drugs: An online ethnography of the Zyzz fandom of recreational bodybuilders. International Journal of Drug Policy, 39, 78-85. doi:https://doi.org/10.1016/i.drugpo.2016.08.012

van Amsterdam, J., Nutt, D., Phillips, L., \& van den Brink, W. (2015). European rating of drug harms. Journal of Psychopharmacology, 29(6), 655-660. doi:10.1177/0269881115581980

van Amsterdam, J., Opperhuizen, A., \& Hartgens, F. (2010). Adverse health effects of anabolicandrogenic steroids. Regulatory Toxicology and Pharmacology, 57(1), 117-123. doi:https://doi.org/10.1016/j.yrtph.2010.02.001

van Amsterdam, J., Opperhuizen, A., Koeter, M., \& van den Brink, W. (2010). Ranking the Harm of Alcohol, Tobacco and Illicit Drugs for the Individual and the Population. Eur Addict Res, 16(4), 202-207.

van de Ven, K. (2016). 'Blurred lines': Anti-doping, national policies, and the performance and image enhancing drug (PIED) market in Belgium and The Netherlands. Performance Enhancement \& Health, 4(3), 94-102. doi:https://doi.org/10.1016/i.peh.2016.03.003

van de Ven, K., Dunn, M., \& Mulrooney, K. (2018a). Performance and image enhancing drug (PIED) producers and suppliers: a retrospective content analysis of PIED-provider cases in Australia from 2010-2016. Trends Organ Crim. doi:https://doi.org/10.1007/s12117-018-9348-5

van de Ven, K., Maher, L., Wand, H., Memedovic, S., Jackson, E., \& Iversen, J. (2018b). Health risk and health seeking behaviours among people who inject performance and image enhancing drugs who access needle syringe programs in Australia. Drug and Alcohol Review. doi:10.1111/dar.12831

van de Ven, K., \& Mulrooney, K.J. (2017). Social suppliers: exploring the cultural contours of the performance and image enhancing drug (PIED) market among bodybuilders in the Netherlands and Belgium. International Journal of Drug Policy, 40, 6-15. doi:10.1016/j.drugpo.2016.07.009

van de Ven, K., \& Mulrooney, K.J.D. (2014). Anti-Doping 'on Steroids': Bigger, stronger, and faster. Retrieved from http://ph.au.dk/en/research/research-areas/humanistic-sportresearch/research-unit-for-sports-and-physical-culture/international-network-of-dopingresearch/newsletters/december-2014/inhdr-commentary-van-de-ven-mulrooney/

Volkow, N.D., Poznyak, V., Saxena, S., Gerra, G., \& Network, U.W.I.I.S. (2017). Drug use disorders: impact of a public health rather than a criminal justice approach. World Psychiatry, 16(2), 213-214. doi:10.1002/wps.20428

Walsh, S. (2018). 'Crisis of male ego' could explain hundreds of north-east men taking steroids and other image enhancers. The Press and Journal. Retrieved from https://www.pressandjournal.co.uk/fp/news/north-east/1497458/crisis-of-male-ego-couldexplain-hundreds-of-north-east-men-taking-steroids-and-other-image-enhancers/

Winstock, A.R., \& Nutt, D. (2013). The real driver behind most drug use is pleasure, not dependence. The Guardian. Retrieved from https://www.theguardian.com/commentisfree/2013/apr/18/driverdrug-pleasure-dependence

Zahnow, R., McVeigh, J., Bates, G., Hope, V., Kean, J., Smith, J., \& Campbell, J. (2018). Identifying a typology of men who use anabolic androgenic steroids (AAS). International Journal of Drug Policy, 8(55), 105-112. 
Zahnow, R., McVeigh, J., Ferris, J., \& Winstock, A. (2017). Adverse Effects, Health Service Engagement, and Service Satisfaction Among Anabolic Androgenic Steroid Users. Contemporary Drug Problems, 44(1), 69-83. doi:10.1177/0091450917694268 